Article

\title{
Preparation of Ti-Zr-Based Conversion Coating on 5052 Aluminum Alloy, and Its Corrosion Resistance and Antifouling Performance
}

\author{
Hehong Zhang ${ }^{1,2}$, Xiaofeng Zhang ${ }^{1}$, Xuhui Zhao ${ }^{1, *}$, Yuming Tang ${ }^{1, *}$ and Yu Zuo ${ }^{1}$ \\ 1 Beijing Key Laboratory of Electrochemical Process and Technology for Materials, Beijing University of \\ Chemical Technology, Beijing 100029, China; zhanghhmq@163.com (H.Z.); zhangxf@mail.buct.edu.cn (Xi.Z.); \\ zuoy@mail.buct.edu.cn (Y.Z.) \\ 2 China Special Equipment Inspection and Research Institute, Beijing 100029, China \\ * Correspondence: xhzhao@mail.buct.edu.cn (Xu.Z.); tangym@mail.buct.edu.cn (Y.T.); \\ Tel.: +86-10-6443-4908 (Xu.Z.); +86-10-6443-4908 (Y.T.)
}

Received: 14 September 2018; Accepted: 10 November 2018; Published: 12 November 2018

check for updates

\begin{abstract}
A chemical conversion coating on 5052 aluminum alloy was prepared by using $\mathrm{K}_{2} \mathrm{ZrF}_{6}$ and $\mathrm{K}_{2} \mathrm{TiF}_{6}$ as the main salts, $\mathrm{KMnO}_{4}$ as the oxidant and $\mathrm{NaF}$ as the accelerant. The surface morphology, structure and composition were analyzed by SEM, EDS, FT-IR and XPS. The corrosion resistance of the conversion coating was studied by salt water immersion and polarization curve analysis. The influence of fluorosilane (FAS-17) surface modification on its antifouling property was also discussed. The results showed that the prepared conversion coating mainly consisted of $\mathrm{AlF}_{3} \cdot 3 \mathrm{H}_{2} \mathrm{O}$, $\mathrm{Al}_{2} \mathrm{O}_{3}, \mathrm{MnO}_{2}$ and $\mathrm{TiO}_{2}$, and exhibited good corrosion resistance. Its corrosion potential in $3.5 \mathrm{wt} \%$ $\mathrm{NaCl}$ solution was positively shifted about $590 \mathrm{mV}$ and the corrosion current density was dropped from 1.10 to $0.48 \mu \mathrm{A} \mathrm{cm}^{-2}$. By sealing treatment in $\mathrm{NiF}_{2}$ solution, its corrosion resistance was further improved yielding a corrosion current density drop of $0.04 \mu \mathrm{A} \mathrm{cm}{ }^{-2}$. By fluorosilane (FAS-17) surface modification, the conversion coating became hydrophobic due to low-surface-energy groups such as $\mathrm{CF}_{2}$ and $\mathrm{CF}_{3}$, and the contact angle reached $136.8^{\circ}$. Moreover, by FAS- 17 modification, the corrosion resistance was enhanced significantly and its corrosion rate decreased by about 25 times.
\end{abstract}

Keywords: conversion coating; aluminum alloy; fluorosilane modification; corrosion resistance; antifouling performance

\section{Introduction}

Aluminum alloys are widely used in various fields such as aerospace, automotive, transportation, petrochemical, construction and electronics industries due to their high strength, good thermal and electrical conductivity, good plasticity and lack of magnetism [1,2]. However, aluminum alloys have a poor corrosion resistance due to their active chemical property. Additionally, aluminum alloys are vulnerable to pollution by organics, so it is necessary to treat the surface of aluminum alloys before application. Common approaches to improve the corrosion resistance of aluminum alloys include anodic oxidation, electroplating, microarc oxidation, chemical conversion coating and other techniques. Conventional chromate conversion coatings exhibit excellent corrosion resistance and "self-healing" function, but are extremely toxic carcinogens and cause serious environmental pollution [3]. The research for chromate conversion coating substitutes has more than 20 years of history, but in the last few years it has become more intense, due to the fact that in 2007 the chromate coatings were banned from European industry except from aeronautics applications that still have a permission to use these treatments. As the ROHS (Restriction of Hazardous Substances), ELV (End-of-Life Vehicle) and WEEE (Waste Electrical and Electronic Equipment) regulations launched, 
hexavalent chromium was strictly limited [4]. The research of non-chromate conversion coatings has become a central issue. Numerous non-chromate conversion coatings were investigated, such as a Mo-based conversion coating [4], Ce-based conversion coatings [2,5,6], Ti-based conversion coating [7], Zr-based conversion coating [8], Mn-based conversion coating [9], phosphate conversion coating [10], V-based conversion coating [11], and Ti-Zr-based conversion coating [12]. Because of their incomparable advantage of being environmentally friendly, these non-chromate conversion coatings could be used as suitable alternatives.

The Ti-Zr-based conversion coating has a high corrosion resistance and is already applied in industry. Many researchers have pointed out that Ti-Zr-based conversion coatings are optimal to achieve the same performance as the chromate conversion coatings [12-18]. Liu et al. studied on adhesion strength and corrosion resistance of a Ti-Zr aminotrimethylene phosphonic acid composite conversion coating on 7A52 aluminum alloy [12]. Nordlienet et al. fabricated Ti/Zr oxide film on AA6060 aluminum alloys and studied the mechanism of film formation [13]. Lunder et al. also fabricated a Ti/Zr-based conversion coating on AA6060 aluminum alloys-the results showed that the conversion coating slightly restrained the cathodic activity, but was expected to improve the corrosion resistance of aluminum significantly [14]. Guan et al. developed a novel Ti-Zr-based conversion coating on electrogalvanized steel-the corrosion current density of the substrate decreased by two orders of magnitude due to the formation of the coating, which improved the corrosion resistance significantly [15]. Yi et al. fabricated a golden Ti-Zr-based conversion coating on AA6063 aluminum alloys; the mechanism of film formation was also discussed. Their results found a reduced corrosion current density and a significantly improved corrosion resistance [16]. Coloma et al. developed several $\mathrm{Cr}$-free conversion coatings based on inorganic salts $(\mathrm{Zr} / \mathrm{Ti} / \mathrm{Mn} / \mathrm{Mo})$, which can significantly improve the corrosion resistance of aluminum alloys, although these coatings do not still meet the stringent requirements of the aircraft industry [17]. Zhu et al. developed a Ti/Zr/V conversion coating on the surface of aluminum alloy 6063 (AA6063), and reported that its anticorrosion performance and adhesion properties were superior to that of chromate conversion coating [18]. However, the traditional Ti-Zr-based conversion treatment is mainly aimed at improving the anticorrosion performance and seldom enhances the antifouling performance. In this work, we developed a Ti-Zr-based conversion coating on 5052 aluminum alloys, using fluorosilane (FAS-17) modification as a post-treatment. The results indicate that both the anticorrosion performance and the antifouling performance of aluminum alloys are improved.

\section{Materials and Methods}

5052 aluminum alloy foils, whose chemical composition is composed of $\mathrm{Mg} 2.2 \%-2.8 \%$, $\mathrm{Si} 0.25 \%$, $\mathrm{Cu} 0.1 \%$, Zn $0.1 \%$, Mn $0.1 \%$, Fe $0.4 \%$, Cr $0.15 \%-0.35 \%$ and balance of $\mathrm{Al}$, were used as substrate. The samples were first cut to dimensions of $20 \mathrm{~mm} \times 10 \mathrm{~mm} \times 2 \mathrm{~mm}$, abraded with abrasive papers up to 1000 times, then were wiped with acetone, degreased in an alkali solution $\left(\mathrm{NaOH}: 40 \mathrm{~g} \mathrm{~L}^{-1}\right.$, $\mathrm{Na}_{2} \mathrm{CO}_{3}: 20 \mathrm{~g} \mathrm{~L}^{-1}, \mathrm{Na}_{3} \mathrm{CH}_{5} \mathrm{O}_{7} \cdot 2 \mathrm{H}_{2} \mathrm{O}: 2.28 \mathrm{~g} \mathrm{~L}^{-1}$, SDBS: $1.5 \mathrm{~g} \mathrm{~L}^{-1}$ ) at $50^{\circ} \mathrm{C}$ for about $5 \mathrm{~min}$, followed by acid pickling $\left(\mathrm{HNO}_{3}: 211 \mathrm{~mL} \mathrm{~L}^{-1}\right)$ at room temperature for about $2 \mathrm{~min}$, and finally rinsed with deionized water.

The conversion treatment solution was composed of $\mathrm{KMnO}_{4}: 2-4 \mathrm{~g} \mathrm{~L}^{-1}, \mathrm{NaF}: 0.1 \mathrm{~g} \mathrm{~L}^{-1}, \mathrm{~K}_{2} \mathrm{ZrF}_{6}$ : $0.25-0.75 \mathrm{~g} \mathrm{~L}^{-1}, \mathrm{~K}_{2} \mathrm{TiF}_{6}: 1-1.5 \mathrm{~g} \mathrm{~L}^{-1}$. The $\mathrm{pH}$ was about 2, the treatment temperature was in the range of $70-80^{\circ} \mathrm{C}$ and the treatment time was about $5 \mathrm{~min}$. The sealing treatment solution was composed of $\mathrm{NiSO}_{4} \cdot 6 \mathrm{H}_{2} \mathrm{O}: 1.2 \mathrm{~g} \mathrm{~L}^{-1}, \mathrm{NaF}: 0.6 \mathrm{~g} \mathrm{~L}^{-1}$, the treatment time was about $30 \mathrm{~min}$ and treatment temperature was room temperature. After the conversion treatment, the samples were treated in boiling water for about $30 \mathrm{~min}$, then immersed in fluorosilane (FAS-17: $2 \mathrm{~g}$, isopropanol: $180 \mathrm{~g}, \mathrm{H}_{2} \mathrm{O}: 18 \mathrm{~g}$ ) at room temperature for about $24 \mathrm{~h}$. The samples were then dried in oven at $120^{\circ} \mathrm{C}$ for about $30 \mathrm{~min}$.

Scanning electron microscopy (SEM, S-4700, Hitachi, Tokyo, Japan) was used to investigate the surface morphology and energy dispersive X-ray spectroscopy (EDS, Isis 300, Oxford Instrument, Oxfordshire, UK) was used to analyze the chemical composition of the coating. The operating potential 
of the field emission source was $20 \mathrm{kV}$. The samples were coated with gold to preclude the charging effect during measurement.

A Fourier-transform infrared spectrometer (FT-IR, Tensor27, Bruker Co., Hamburg, Germany) was used to analyze the atomic groups in the coating, and infrared spectra were recorded in absorbance units in the $400-4000 \mathrm{~cm}^{-1}$ range. The spectra of powder samples were tested with $\mathrm{KBr}$ pellet method. The scan number was 30 and the spectral resolution was $16 \mathrm{~cm}^{-1}$.

The surface composition of the coating was then measured via X-ray photoelectron spectroscopy (XPS) with a monochromated $\mathrm{Al} \mathrm{K} \alpha$ source $(1486.6 \mathrm{eV})$. The operating pressure was less than $8-10 \mathrm{~Pa}$. The measured binding energy (BE) range for the wide scan spectrum was from 0 to $1350 \mathrm{eV}$ in $1 \mathrm{eV}$ steps without sputtering. The binding energy values were calibrated by the $\mathrm{C} 1 \mathrm{~s}$ peak at $285 \mathrm{eV}$. The data were fitted by XPSPEAK v4.1 software.

The corrosive behavior was studied with a weight loss test and polarization measurement. The tests were both carried out in $3.5 \mathrm{wt} \% \mathrm{NaCl}$ solution. The weight loss test was carried out at $45{ }^{\circ} \mathrm{C}$ for $504 \mathrm{~h}$. Specimens for the polarization test were mounted in phenolic resin leaving an exposed area of $1 \mathrm{~cm}^{2}$. Polarization measurement was performed using a CS350 electrochemical workstation. The potential scanning range was $-0.3-1.5 \mathrm{~V}$ relative to the open circuit potential (OCP) and the scanning rate was $10 \mathrm{mV} \mathrm{s}^{-1}$. The reference electrode was a saturated calomel electrode (SCE), the counter electrode was a Pt electrode and the specimen was a working electrode.

The water contact angles were measured by Dataphysics OCA 20 with a distilled water droplet volume of $4 \mu \mathrm{L}$. A simulated pollutant test was carried out to analyze the antifouling performance. The pollutant was a mixture of tallow, liquid paraffin, carbon black, and fluorescent substance. The fluorescent substance in residue was observed by a fluorescence microscope (BX53) after the pollutant was removed from the coating. All the reagents used were of analytic grade. The cleaning rate was calculated through Equation (1). Three trials were performed in order to ensure the accuracy of the test. Average cleaning rate was obtained.

$$
\text { Cleaning rate }=\left(m_{2}-m_{3}\right) /\left(m_{2}-m_{1}\right) \times 100 \%
$$

where $m_{1}$ : mass of samples before pollutant coated; $m_{2}$ : mass of samples after pollutant coated; $m_{3}$ : mass of samples after pollutant removed.

\section{Results and Discussion}

\subsection{Characterizations of the Coating}

A compact yellow conversion coating was prepared on the 5052 aluminum alloys after the conversion treatment. Figure 1 shows the surface morphologies of the coating. A continuous, compact and well-covered coating can be seen by comparing Figure $1 \mathrm{a}, \mathrm{b}$. The obtained coatings are smooth; however, they became coarse after FAS-17 modification treatment as seen in Figure 1c,d. Some micro-protrudes were generated on the coating surface [19]. These micro-protrudes may increase the roughness of the surface and decrease the surface energy, which improves the hydrophobic properties of the coating. All of these characteristics may be related to the antifouling performance of the coating.

Figure 2 shows the EDS spectra of the coating. The conversion coating contains $\mathrm{Al}, \mathrm{O}, \mathrm{F}, \mathrm{Mg}, \mathrm{Zr}$, $\mathrm{Ti}$ and $\mathrm{Mn}$ as shown in Figure 2a. The concentration of $\mathrm{Al}, \mathrm{Ti}$ and $\mathrm{Mn}$ is relatively high, and they may exist in oxide or fluoride states. The concentration of $\mathrm{Zr}$ is relatively low, and it is usually covered by other elements [20,21]. After the FAS-17 post treatment, $C$ and Si elements emerged (Figure $2 b$ ). As is well known, the FAS-17 contains $\mathrm{C}-\mathrm{F}$ and $\mathrm{Si}-\mathrm{O}$ atom groups, and the spectrum indicated that a fluorosilane film was produced on the surface of the conversion coating after FAS-17 modification. 

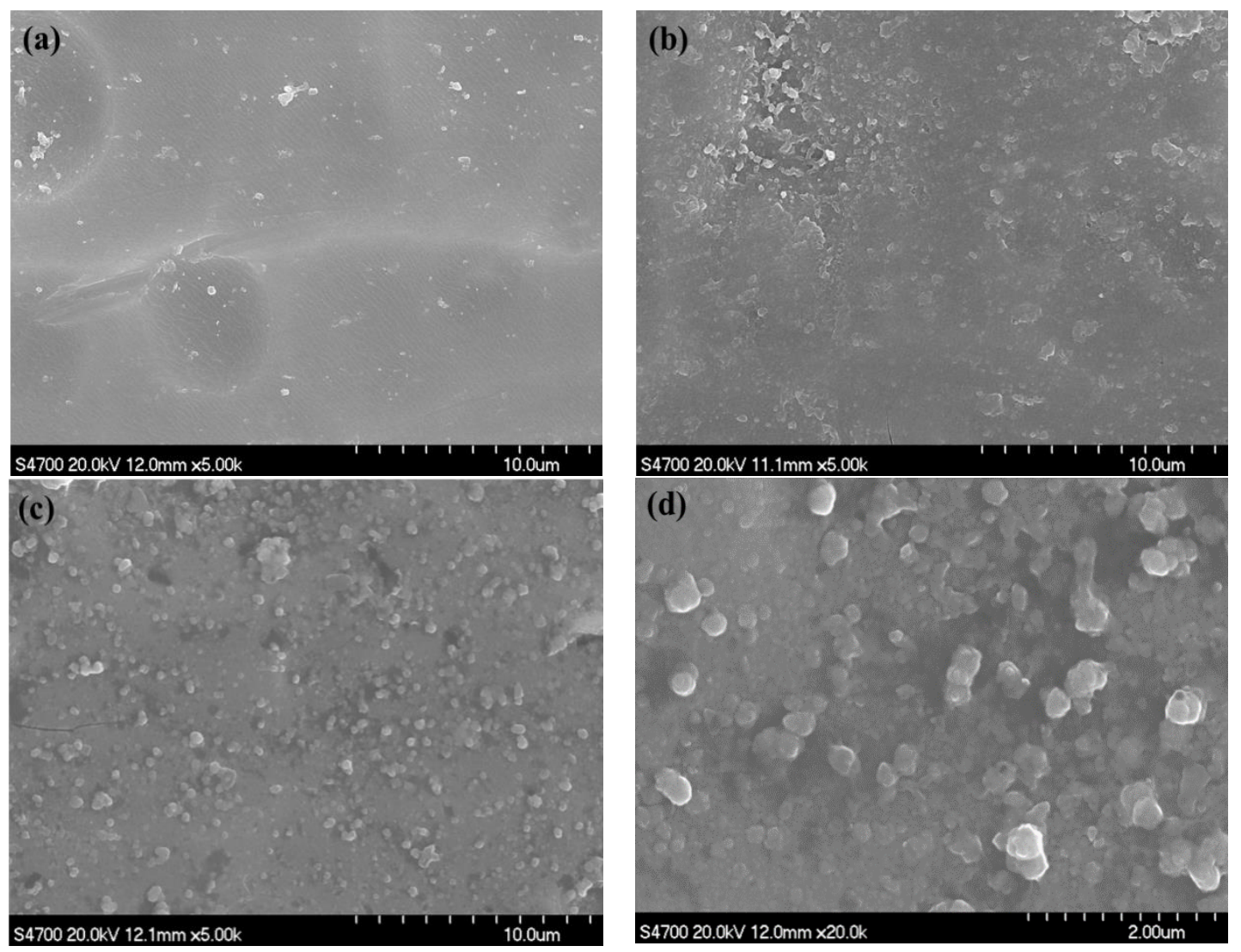

Figure 1. SEM images of conversion-coated 5052 aluminum alloy: (a) Al substrate; (b) conversion coating; (c,d) after FAS-17 modification.



(a)

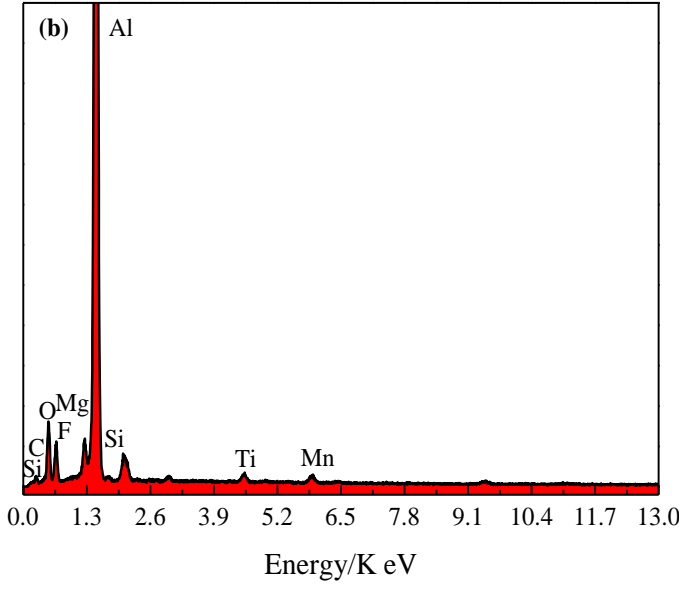

(b)

Figure 2. EDS spectra of conversion-coated 5052 aluminum alloy: (a) before FAS-17 modification, (b) after FAS-17 modification.

FT-IR was utilized to analyze the compositions of the coating. Figure 3 shows the FT-IR spectra of the conversion before and after FAS-17 modification. As shown in Figure 3a, the absorption around $3433 \mathrm{~cm}^{-1}$ is assigned to the absorptions of a hydroxyl group. The characteristic peaks at the range of $2839-2978 \mathrm{~cm}^{-1}$ are assigned to the absorptions of $\mathrm{C}-\mathrm{H}[16,22]$. The characteristic peak at around $1631 \mathrm{~cm}^{-1}$ is assigned to the absorptions of Al-O. The characteristic peak at $1409 \mathrm{~cm}^{-1}$ is assigned to the absorptions of $\mathrm{Mn}-\mathrm{O}$. The characteristic peak at $1043 \mathrm{~cm}^{-1}$ is assigned to the absorptions of $\mathrm{S}=\mathrm{O}$ in surfactant. The characteristic peak at $859 \mathrm{~cm}^{-1}$ is assigned to the absorptions 
of Ti-O and the characteristic peak at $587 \mathrm{~cm}^{-1}$ is assigned to the absorptions of $\mathrm{Al}-\mathrm{F}$ [23]. A thin fluorosilane film was adhered to the conversion coating by FAS-17 modification. The spectrum shows some new characteristic peaks located in the range of $1050-1205 \mathrm{~cm}^{-1}$ and $1383-1454 \mathrm{~cm}^{-1}$. The characteristic peaks at the range of $1050-1205 \mathrm{~cm}^{-1}$ are assigned to the absorptions of $\mathrm{C}-\mathrm{F}$ in $\mathrm{CF}_{3}$ and $\mathrm{CF}_{2}$ [24]. The characteristic bands at the range of $1383-1454 \mathrm{~cm}^{-1}$ are assigned to the absorptions of $\mathrm{CF}_{3}[23,25,26]$. The characteristic peak at $1204 \mathrm{~cm}^{-1}$ is assigned to the absorptions of $\mathrm{CF}_{2}$ [25]. The characteristic peaks at 1050 and $880 \mathrm{~cm}^{-1}$ are assigned to the absorptions of $\mathrm{Si}-\mathrm{O}-\mathrm{C}$ and $\mathrm{Si}-\mathrm{O}$, respectively $[23,24]$.
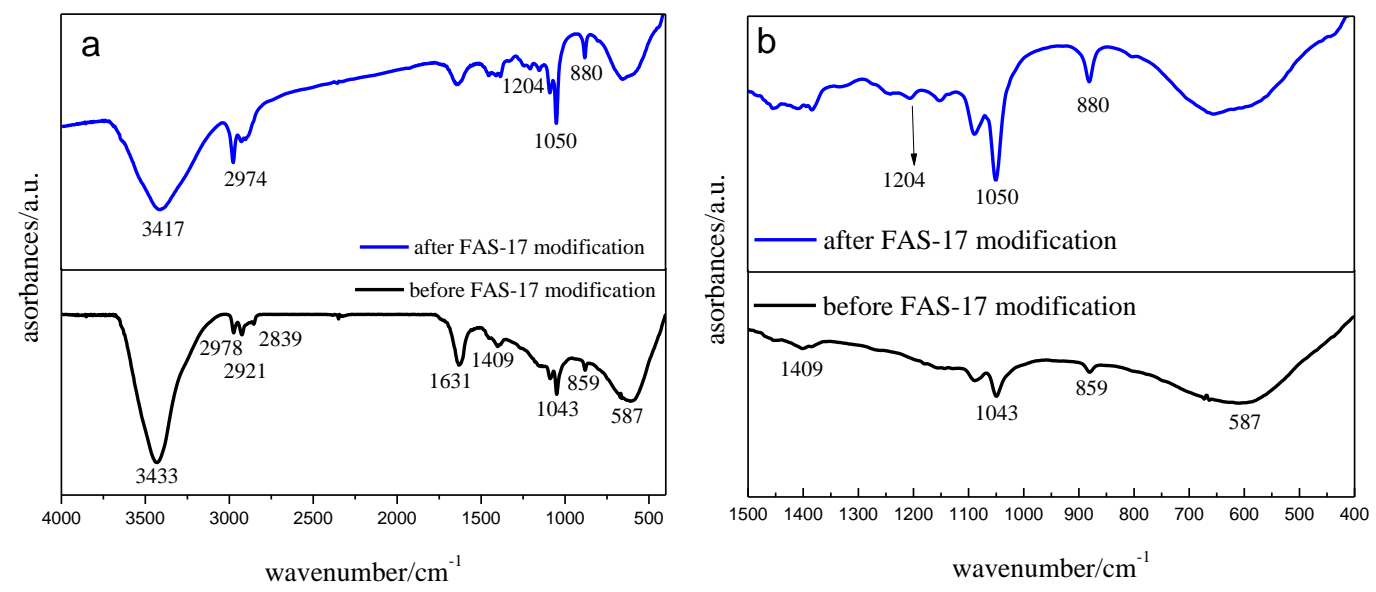

Figure 3. FT-IR spectra of conversion-coated 5052 aluminum alloy before FAS-17 modification and after FAS-17 modification: (b) is (a) with partial enlargement.

XPS was utilized to characterize the detailed variations of element information on the conversion coating surface. Figure 4a shows the overview XPS spectra of the conversion coating. As illustrated in Figure $4 \mathrm{a}$, the conversion coating is mainly composed of $\mathrm{Al}, \mathrm{Mn}, \mathrm{Ti}, \mathrm{F}, \mathrm{O}$ and $\mathrm{C}$. The peak of $\mathrm{C} 1 \mathrm{~s}$ may be attributed to the impurities and surfactant, but considering its low concentration, we omitted to perform a detailed analysis. Figure $4 b-f$ shows the detailed peaks of Al2p, F1s Mn2p, Ti2p, and O1s spectra, respectively. The A12p core-level spectrum (Figure $4 \mathrm{~b}$ ) can be curve-fitted into three peak components with binding energies at about $76.9,75.7$ and $74.3 \mathrm{eV}$, which are assigned to $\mathrm{AlF}_{3} \cdot 3 \mathrm{H}_{2} \mathrm{O}$, $\mathrm{AlO}_{x} / \mathrm{Al}$ and $\mathrm{Al}_{2} \mathrm{O}_{3}$ [12]. The F1s spectrum (Figure 4c) shows only one peak at $686.3 \mathrm{eV}$, corresponding to the $\mathrm{AlF}_{3} \cdot 3 \mathrm{H}_{2} \mathrm{O}$ [12]. The Mn2p peaks (Figure $4 \mathrm{~d}$ ) are composed of three peak structures with binding energies at about 653.5, 642.2 and $641.3 \mathrm{eV}$; we assign these to the $\mathrm{MnO}_{2}$ [17-19]. The Ti2p spectrum (Figure 4e) shows two fitted peaks at 464.0 and $458.2 \mathrm{eV}$ corresponding to the $\mathrm{TiO}_{2}[16,27]$. The details of O1s peaks (Figure 4f) reveal three peak structures with binding energies at about 532.4, 531.6 and $530.1 \mathrm{eV}$, which are assigned to the oxides of $\mathrm{Ti}, \mathrm{Al}$ and $\mathrm{Mn}$, respectively [16].
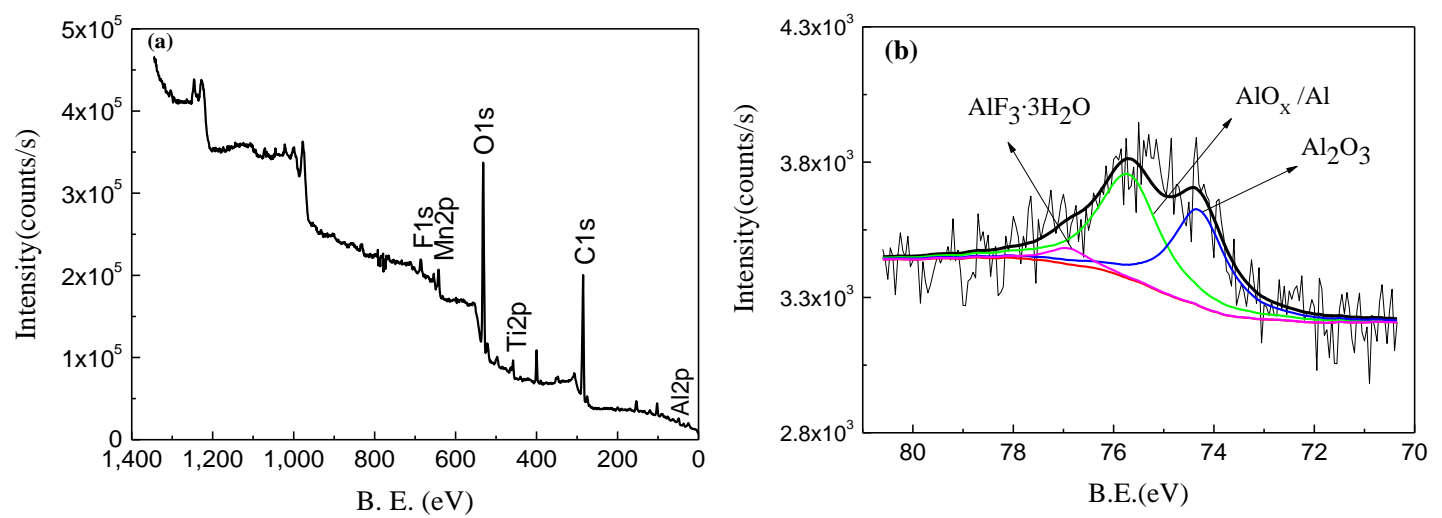

Figure 4. Cont. 

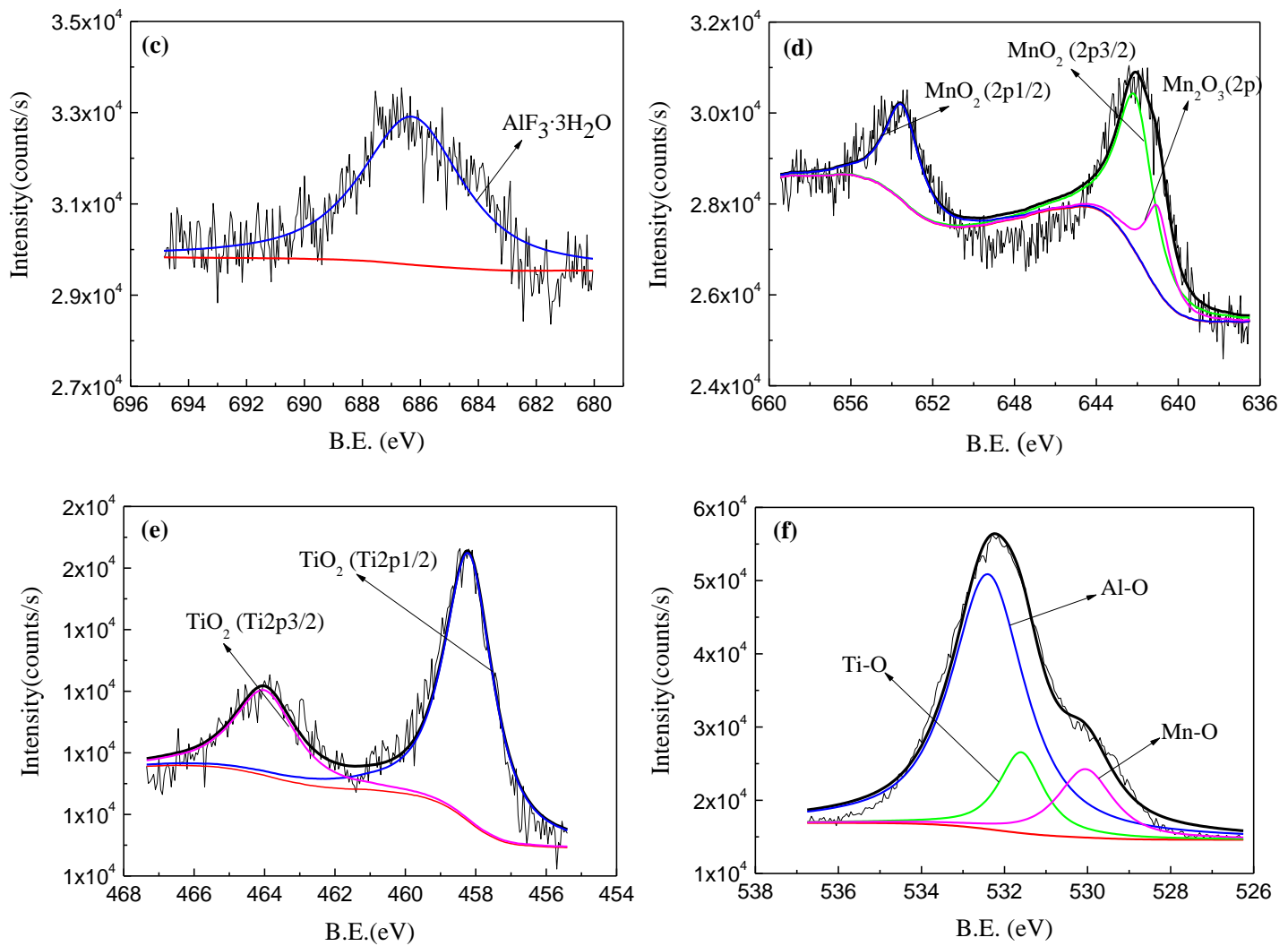

Figure 4. XPS spectra of conversion-coated 5052 aluminum alloy: (a) the wide-scan spectrum, (b) Al2p spectrum, (c) F1s spectrum, (d) Mn2p spectrum, (e) Ti2p spectrum, and (f) O1s spectrum.

As described previously, thin fluorosilane films were produced onto the surface of the conversion coating after the FAS-17 modification. The elements on the surface may also change after this step. Figure 5 shows the XPS spectra of the conversion coating after FAS-17 modification. As illustrated in Figure $5 a$, the intensity of the F1s peak increased and the Si2s and Si2p spectra emerged. The C1s spectrum is composed of six fitted peaks with the binding energies at 294.1, 291.8, 286.14, 285.8, 285.2 and $284.8 \mathrm{eV}$, which are assigned to the $\mathrm{CF}_{3}, \mathrm{CF}_{2}, \mathrm{C}-\mathrm{O}, \mathrm{CH}_{3}, \mathrm{C}-\mathrm{C}$ and $\mathrm{CH}_{2}$ groups, respectively $[19,28,29]$.
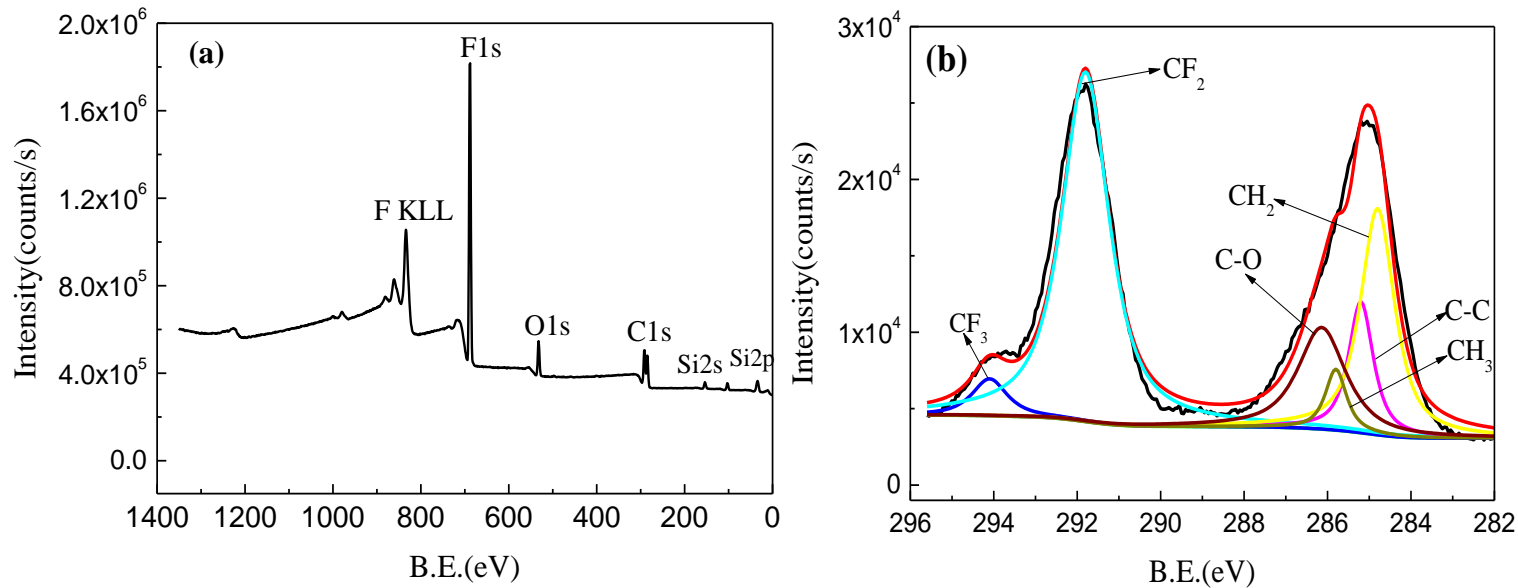

Figure 5. XPS spectra of conversion-coated 5052 aluminum alloy after FAS-17 modification: (a) the wide-scan spectrum, (b) C1s spectrum. 
The results of EDS, FT-IR and XPS show that the main components are $\mathrm{AlF}_{3} \cdot 3 \mathrm{H}_{2} \mathrm{O}, \mathrm{Al}_{2} \mathrm{O}_{3}$, $\mathrm{MnO}_{2}$ and $\mathrm{TiO}_{2}$. A thin fluorosilane film formed on the surface of the conversion coating after FAS-17 modification.

\subsection{Corrosion Resistance of Coating Samples}

Figure 6 shows the polarization curves of the substrate before and after conversion treatment. The fitting results are shown in Table 1 . It is known that the corrosion current density $\left(I_{\text {corr }}\right)$ is one of the most important parameters to evaluate the corrosion resistance of metal substrate [16]. A smaller $I_{\text {corr }}$ value corresponds to better corrosion resistance. As shown in Figure 6 and Table 1 , the $I_{\text {corr }}$ decreased to $0.48 \mu \mathrm{A} \mathrm{cm}^{-2}$ from $1.10 \mu \mathrm{A} \mathrm{cm}^{-2}$ after conversion treatment, it decreased to $0.04 \mu \mathrm{A} \mathrm{cm}^{-2}$ after sealing treatment, and it dropped to $0.005 \mu \mathrm{A} \mathrm{cm}{ }^{-2}$ by FAS-17 modification. The corrosion potential ( $\left.E_{\text {corr }}\right)$ positively shifted from -1196 to $-590 \mathrm{mV}$ by conversion treatment and FAS-17 modification. It can be concluded that the corrosion resistance of $\mathrm{Al}$ samples was improved significantly by conversion treatment and FAS-17 modification.

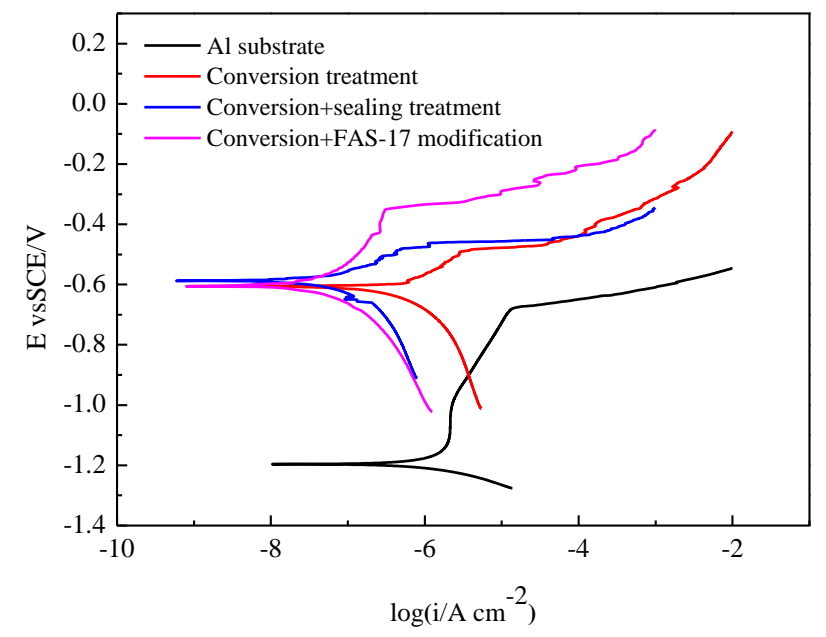

Figure 6. The polarization curves of 5052 aluminum alloy samples after different treatments.

Table 1. Fitting results of the polarization curves for 5052 aluminum alloy after different treatments.

\begin{tabular}{ccc}
\hline Samples & $E_{\text {corr }}(\mathbf{m V})$ & $I_{\text {corr }}\left(\mu \mathbf{A ~ c m}^{-2}\right)$ \\
\hline Al substrate & -1196 & 1.10 \\
Conversion treatment & -605 & 0.48 \\
Conversion + sealing treatment & -587 & 0.04 \\
Conversion + FAS-17 modification & -590 & 0.005 \\
\hline
\end{tabular}

A salt water immersion test was utilized to further analyze corrosion resistance of the conversion coating. The results indicated that the corrosion resistance of aluminum alloy substrate was significantly improved by conversion treatment. The corrosion rate of aluminum alloy substrate in $3.5 \% \mathrm{NaCl}$ solution dropped from $0.240 \mathrm{~g} \cdot \mathrm{m}^{-2} \cdot \mathrm{h}^{-1}$ to $0.046 \mathrm{~g} \cdot \mathrm{m}^{-2} \cdot \mathrm{h}^{-1}$, and it further dropped to $0.0118 \mathrm{~g} \cdot \mathrm{m}^{-2} \cdot \mathrm{h}^{-1}$ after FAS-17 modification.

\subsection{Antifouling Performance Analysis}

It has been reported that the surface is usually hydrophobic after FAS-17 modification [29-32]. Figure 7 shows the contact angle of conversion coating vs water after FAS-17 modification. It can be seen that the contact angle of conversion coating increased from $84.6^{\circ}$ to $136.8^{\circ}$; this implies hydrophilicity. 

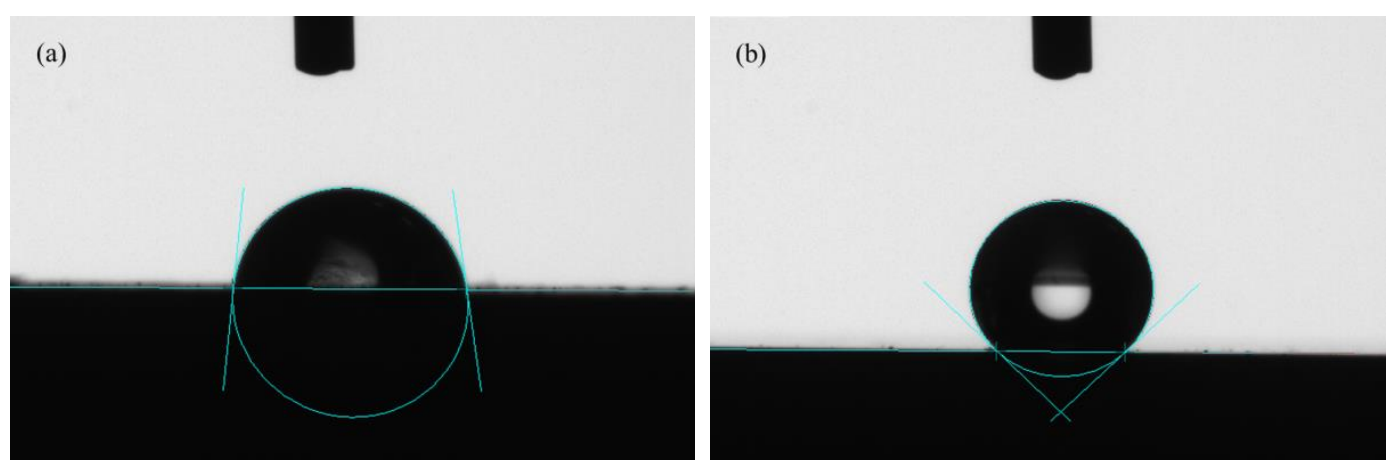

Figure 7. The contact angle of conversion-coated 5052 aluminum alloy: (a) before FAS-17 modification, (b) after FAS-17 modification.

The simulated pollutant test was carried out on the FAS-17-modified coating in order to analyze the antifouling performance. Figure 8 shows the cleaning rate of aluminum alloy samples through different treatments. As shown in Figure 7, the cleaning rate of samples without any treatment, with pretreatment, and with conversion treatment are $91 \%, 81 \%$ and $83 \%$, respectively. Samples have a higher cleaning rate after FAS-17 modification. Taking the corrosion resistance and antifouling performance into account, the latter exhibits better antifouling performance. As is proved previously, a thin fluorosilane film formed on the surface of the conversion coating. Micro-protrudes were generated on the surface and some atom groups such as $\mathrm{CF}_{3}$ and $\mathrm{CF}_{2}$, which can lower the surface energy, were seen; these groups eventually resulted in a hydrophobic surface. The hydrophobic surface improved the antifouling performance of the conversion coating.

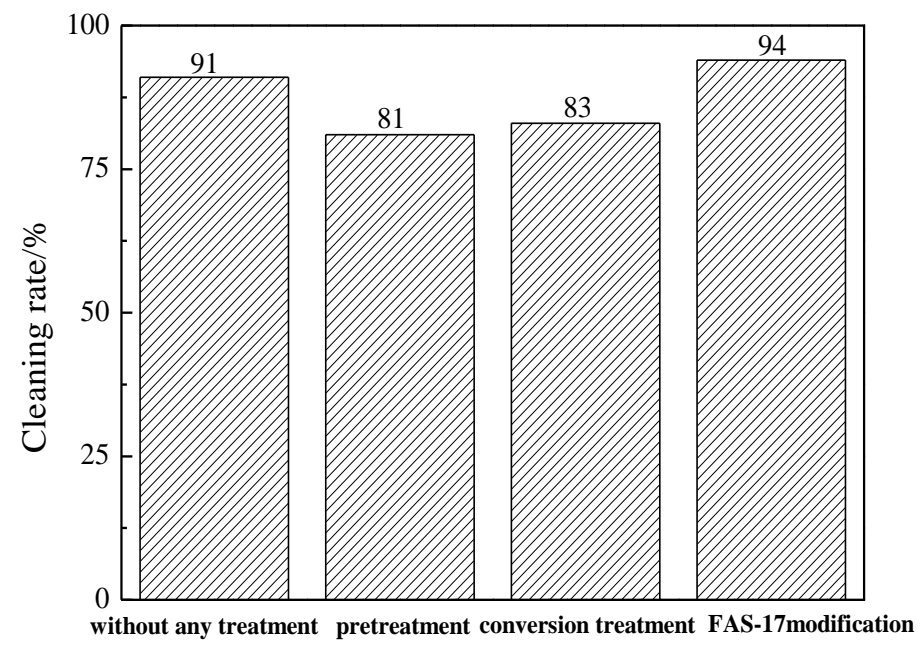

Figure 8. The cleaning rate of 5052 aluminum alloy samples under different treatments.

In order to analyze the antifouling performance intuitively, fluorescence microscopy was used to observe the surface of the conversion coating. Figure 9 shows the fluorescence images of conversion coating. Figure $9 \mathrm{a}, \mathrm{b}$ are the fluorescence images of aluminum alloy samples after conversion treatment and after FAS-17 modification, respectively. It can be seen from the images that no green fluorescence substance can be detected [33], indicating that the fluorescence substance comes from coated pollutant, not the FAS-17. Figure $9 \mathrm{c}, \mathrm{d}$ are the fluorescence images of coating after pollutant was removed. By comparing the Figure $9 \mathrm{c}, \mathrm{d}$, we observe that the samples after FAS-17 modification have less green fluorescence substance and the brightness is relatively small. These results indicate that there is less pollutant left on the surface of the coating after FAS-17 treatment, corresponding to a better antifouling performance. 

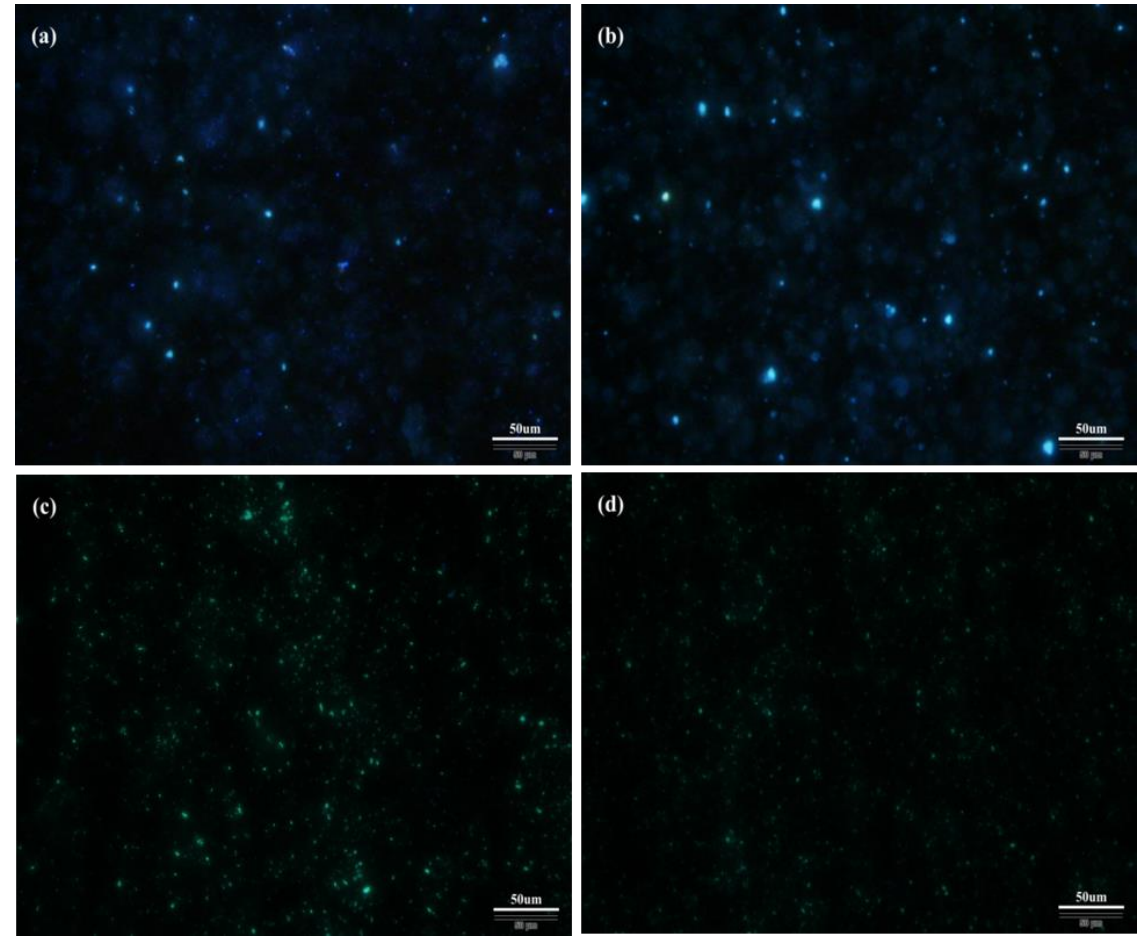

Figure 9. Fluorescence microscope images of the coating before and after the pollutant was removed: before pollutant coated (a) after conversion, (b) after FAS-17 modification; after pollutant removed (c) before FAS-17 modification, (d) after FAS-17 modification.

\section{Conclusions}

Conversion coating was prepared on the surface of 5052 aluminum alloys by using $\mathrm{K}_{2} \mathrm{ZrF}_{6}$ and $\mathrm{K}_{2} \mathrm{TiF}_{6}$ as the main salts, $\mathrm{KMnO} 4$ as the oxidant and $\mathrm{NaF}$ as the accelerant. The coating was mainly composed of $\mathrm{AlF}_{3} \cdot 3 \mathrm{H}_{2} \mathrm{O}, \mathrm{Al}_{2} \mathrm{O}_{3}, \mathrm{MnO}_{2}$ and $\mathrm{TiO}_{2}$.

The $E_{\text {corr }}$ of aluminum alloy samples after conversion treatment and FAS-17 modification positively shifted about $600 \mathrm{mV}$. The $I_{\text {corr }}$ decreased by about three orders of magnitude, and the corrosion resistance significantly improved.

A thin fluorosilane film formed on the surface of the conversion coating after FAS-17 modification. The surface was hydrophobic and the contact angle reached $136.8^{\circ}$. The antifouling performance of the conversion coating improved after the FAS-17 modification, corresponding to a cleaning rate of $94 \%$.

Author Contributions: Conceptualization, Xi.Z. and Xu.Z.; Methodology, H.Z.; software, H.Z.; Validation, H.Z.; Formal Analysis, H.Z.; Investigation, Xu.Z.; Resources, Y.Z.; Data Curation, Xu.Z.; Writing-Original Draft Preparation, H.Z.; Writing—Review and Editing, Y.T.; Visualization, Xu.Z.; Supervision, Xi.Z., Xu.Z., Y.T. and Y.Z.; Project Administration, Xu.Z.; Funding Acquisition, Xu.Z. and Y.Z.

Funding: This research received no external funding.

Conflicts of Interest: The authors declare no conflict of interest.

\section{References}

1. Wang, Z.X.; Ma, Y.L.; Wu, H.P.; Liao, Y.; Lin, Z.H.; Zhang, H.Y.; Zhang, Y.; Mori, K. Preparation and Properties of Silane Coating on 5182 Aluminum Alloy. Surf. Technol. 2018, 5, 256-264. (In Chinese) [CrossRef]

2. Arthanari, S.; Shin, S.K. A simple one step cerium conversion coating formation on to magnesium alloy and electrochemical corrosion performance. Surf. Coat. Technol. 2018, 349, 757-772. [CrossRef]

3. Zhong, X.; Wu, X.S.; Jia, Y.Y.; Liu, Y.L. Self-repairing Vanadium-Zirconium Composite Conversion Coating for Aluminum Alloys. Appl. Surf. Sci. 2013, 280, 489-493. [CrossRef]

4. Liang, C.S.; Lv, Z.F.; Zhu, Y.L.; Xu, S.A.; Wang, H. Protection of Aluminum Foil AA8021 by Molybdate-based Conversion Coatings. Appl. Surf. Sci. 2014, 280, 497-502. [CrossRef] 
5. Valdez, B.; Kiyota, S.; Stoytcheva, M.; Zlatev, R.; Bastidas, J.M. Cerium-based conversion coatings to improve the corrosion resistance of aluminum alloy 6061-T6. Corros. Sci. 2014, 87, 141-149. [CrossRef]

6. Fahrenholtz, W.G.; O'Keefe, M.J.; Zhou, H.F.; Grant, J.T. Characterization of cerium-based conversion coatings for corrosion protection of aluminum alloys. Surf. Coat. Technol. 2002, 155, 208-213. [CrossRef]

7. Xia, X.F.; Gu, Y.Y.; Xu, S.A. Titanium conversion coatings on the aluminum foil AA 8021 used for lithium-ion battery package. Appl. Surf. Sci. 2017, 419, 447-453. [CrossRef]

8. Cerezo, J.; Vandendael, I.; Posner, R.; de Wit, J.H.W.; Mol, J.M.C.; Terryn, H. The effect of surface pre-conditioning treatments on the local composition of Zr-based conversion coatings formed on aluminium alloys. Appl. Surf. Sci. 2016, 366, 339-347. [CrossRef]

9. Rani, R.U.; Sharma, A.K.; Mayanna, S.M.; Bhojraj, H.; Bhandari, D.R. Black permanganate conversion coatings on aluminium alloys for thermal control of spacecraft. Surf. Eng. 2005, 21, 198-203. [CrossRef]

10. Zhao, M.; Li, J.; He, G.; Xie, H.; Fu, Y. An investigation of the effect of a magnetic field on the phosphate conversion coating formed on magnesium alloy. Appl. Surf. Sci. 2013, 282, 499-505. [CrossRef]

11. Ma, Y.B.; Li, N.; Li, D.Y.; Zhang, M.L.; Huang, X.M. Characteristics and corrosion studies of vanadate conversion coating formed on Mg-14wt\%Li-1wt\%Al-0.1wt\%Ce alloy. Appl. Surf. Sci. 2012, 261, 59-67. [CrossRef]

12. Liu, Q.; Cao, X.M.; Du, A.; Ma, RN.; Zhang, X.R.; Shi, T.T.; Fan, Y.Z.; Zhao, X. Investigation on adhesion strength and corrosion resistance of Ti-Zr aminotrimethylene phosphonic acid composite conversion coating on 7A52 aluminum alloy. Appl. Surf. Sci. 2018, 458, 350-359. [CrossRef]

13. Nordlien, J.H.; Walmsley, J.C.; Østerberg, H.; Nisancioglu, K. Formation of a zirconium-titanium based conversion layer on AA 6060aluminum. Surf. Coat. Technol. 2002, 153, 72-78. [CrossRef]

14. Lunder, O.; Simensen, C.; Yu, Y.; Nisancioglu, K. Formation and characterization of Ti-Zr based conversion layers on AA6060 aluminum. Surf. Coat. Technol. 2004, 184, 278-290. [CrossRef]

15. Guan, Y.; Liu, J.G.; Yan, C.W. Novel Ti/Zr Based Non-Chromium Chemical Conversion Coating for the Corrosion Protection of Electrogalvanized Steel. Int. J. Electrochem. Sci. 2011, 6, 4853-4867.

16. Yi, A.H.; Li, W.F.; Du, J.; Mu, S.L. Preparation and Properties of Chrome-free Colored Ti/Zr Based Conversion Coating on Aluminum Alloy. Appl. Surf. Sci. 2012, 258, 5960-5964. [CrossRef]

17. Coloma, P.S.; Izagirre, U.; Belaustegi, Y.; Jorcin, J.B.; Cano, F.J.; Lapeña, N. Chromium free conversion coatings based on inorganic salts $(\mathrm{Zr} / \mathrm{Ti} / \mathrm{Mn} / \mathrm{Mo})$ for aluminum alloys used in aircraft applications. Appl. Surf. Sci. 2015, 354, 24-35. [CrossRef]

18. Zhu, W.; Li, W.F.; Mu, S.L.; Fu, N.Q.; Liao, Z.M. Comparative study on Ti/Zr/V and chromate conversion treated aluminum alloys: Anti-corrosion performance and epoxy coating adhesion properties. Appl. Surf. Sci. 2017, 405, 157-168. [CrossRef]

19. Dong, Y.H.; Li, J.; Zhang, Y.Z.; Hou, Y.L. Self-cleaning Function of $\mathrm{TiO}_{2}$ Nanoparticles Aeronautical Coatings. Chin. J. Rare Met. 2014, 38, 741-748. (In Chinese) [CrossRef]

20. Wu, Y.H.; Li, X.M.; Yang, W.J.; Gao, L. Preparation and Characterization for Permanganate Chemical Conversion Film on LY12 Aluminum Alloy. Surf. Technol. 2011, 40, 81-85. (In Chinese) [CrossRef]

21. Dabala, M.; Brunelli, K.; Napolitani, E.; Magrini, M. Cerium-based Chemical Conversion Coating on AZ63 Magnesium Alloy. Surf. Coat. Technol. 2003, 172, 227-232. [CrossRef]

22. Yu, S.X.; Zhang, R.J.; Tang, Y.F.; Ma, Y.L.; Du, W.C. Composition and Performance of Nanostructured Zirconium Titanium Conversion Coating on Aluminum-Magnesium Alloys. J. Nanomater. 2013, 2013. [CrossRef]

23. Yim, J.H.; Santigo, V.R.; Williams, A.A.; Gougousi, T.; Pappas, D.D.; Hirvonen, J.K. Atmospheric pressure plasma enhanced chemical vapor deposition of hydrophobic coatings using fluorine-based liquid precursors. Surf. Coat. Technol. 2013, 234, 21-32. [CrossRef]

24. Jenog, H.J.; Kim, D.K.; Lee, S.B.; Kwon, S.H.; Kadono, K. Preparation of Water-Repellent Glass by Sol-Gel Process Using Perfluoroalkylsilane and Tetraethoxysilane. J. Colloid Interface Sci. 2001, 235, 130-134. [CrossRef] [PubMed]

25. Wang, T.C.; Chang, L.J.; Yang, S.; Jia, Y.; Wong, C.P. Hydrophobic properties of biomorphic carbon surfaces prepared by sintering lotus leaves. Ceram. Int. 2013, 39, 8165-8172. [CrossRef]

26. Kristalyn, C.B.; Watt, S.; Spanninga, S.A.; Barnard, R.A.; Nguyen, K.; Chen, Z. Investigation of sub-monolayer, monolayer, and multilayer self-assembled semifluorinated alkylsilane films. J. Colloid Interface Sci. 2011, 353, 322-330. [CrossRef] [PubMed] 
27. Zhang, J.J.; Li, W.F.; Du, J.; Han, D.; Zheng, X.P. Investigation of the Ce-Mn conversion coating on 6063 aluminum alloy. Chin. Sci. Bull. 2010, 17, 1734-1737. (In Chinese) [CrossRef]

28. Yan, L.L.; Wang, K.; Wu, J.S.; Ye, L. Characterization of fluoroalkylsilane monolayer on polystyrene sphere arrays after plasma treatment. Surf. Sci. 2007, 601, 1394-1402. [CrossRef]

29. Saleema, N.; Sarkar, D.K.; Paynter, R.W.; Chen, X.G. Superhydrophobic Aluminum Alloy Surfaces by a Novel One-Step Process. ACS Appl. Mater. Interfaces 2010, 2, 2500-2502. [CrossRef] [PubMed]

30. Saleema, N.; Sarkar, D.K.; Paynter, R.W.; Chen, X.G. Chemical Nature of Superhydrophobic Aluminum Alloy Surfaces Produced via a One-Step Process Using Fluoroalkyl-Silane in a Base Medium. ACS Appl. Mater. Interfaces 2011, 3, 4775-4781. [CrossRef] [PubMed]

31. Gao, R.; Wang, J.; Zhang, X.F.; Yan, H.J.; Yang, W.L.; Liu, Q.; Zhang, M.L.; Liu, L.H.; Takahashi, K. Fabrication of superhydrophobic magnesium alloy through theoxidation of hydrogen peroxide. Colloid Surf. A 2013, 436, 906-911. [CrossRef]

32. Wankhede, R.G.; Morey, S.; Khanna, A.S.; Birbilis, N. Development of water-repellent organic-inorganic hybrid sol-gel coatings on aluminum using short chain perfluoro polymer emulsion. Appl. Surf. Sci. 2013, 283, 1051-1059. [CrossRef]

33. Dun, Y.C.; Zhao, X.H.; Tang, Y.M.; Dino, S.; Zuo, Y. Microstructure and corrosion resistance of a fluorosilane modified silane-graphene film on 2024 aluminum alloy. Appl. Surf. Sci. 2018, 437, 152-160. [CrossRef]

(C) 2018 by the authors. Licensee MDPI, Basel, Switzerland. This article is an open access article distributed under the terms and conditions of the Creative Commons Attribution (CC BY) license (http://creativecommons.org/licenses/by/4.0/). 